\title{
The outcome of Antegrade Cerebral Perfusion during Deep Hypothermic Circulatory Arrest in Pediatric Arch Surgery
}

\author{
Hyam Refaat Tantawi ${ }^{1}$; Mohamed Abdel Hafez ${ }^{2}$ \\ 1.Pediatric department, Ain Shams University, 2.Cardiothoracic department, Faculty of Medicine - \\ Cairo University
}

\begin{abstract}
Background: Techniques for the surgical correction of aortic aneurysms have steadily improved since the first described successful repair, Despite these improvements, postoperative neurological complications remain a major factor in determining an adverse outcome. Complex aortic arch reconstruction in neonates and children is performed typically under deep hypothermic circulatory arrest. Aim: The study aimed at examining the effect of clinical impact, particularly neurologic complications, of deep hypothermic circulatory arrest in pediatric arch surgery and to summarize the early outcomes. Patients and method: One-handed and fourteen underwent full-term babies were enrolled in the present study.The maximum age was 20 weeks, arch surgery included Norwood, arch reconstruction for hypoplastic arch and interrupted aortic arch. Healthy neurological status preoperative was included between January 2011 and October 2015. The medical records were reviewed for preoperative diagnosis of patients which included age at the time of operation, sex and diagnosis of the patients. Operative details including type of the operation, duration of cross-clamp and deep hypothermic circulatory arrest timing were documented. The deep hypothermic circulatory arrest was conducted at $20{ }^{\circ} \mathrm{C}$. Postoperative outcomes, neurological complications including seizers, cerebral infarct, and duration of hospital stay were recorded. Results: The study noted that the incidence of postoperative complications such as seizure \& bleeding was markedly $5.3 \% \& 1.8 \%$ of the studied pediatric patients. Conclusion: The results concluded that the aortic arch reconstruction with Antegrade cerebral perfusion during the deep hypothermic circulatory arrest was accompanied by a lower risk of neurological complications. Recommendations: Long-term neurodevelopmental follow-up of these children is required to evaluate the late outcomes of Antegrade cerebral perfusion.
\end{abstract}

Keywords: Aortic Arch Surgery, Antegrade Cerebral Perfusion, Deep Hypothermic Circulatory Arrest, Neurological Complications.

\section{Introduction:}

Aortic arch surgery represents a technically demanding and high-risk cardiovascular operation ${ }^{1,2}$. Although neurologic injury in children with congenital heart disease is recognized as having a multifactorial origin, considerable effort is being made to limit any aggravating factors occurring at the time of repair ${ }^{(3,4,5)} 19,33$. Therefore, the Surgery on the aortic arch is challenging because of the need to ensure a bloodless surgical field and adequate cerebral protection $^{6,7,8}$. Protection of cerebrum, which is the most vulnerable target at the aortic arch surgery, is crucial because deterioration of neurological status has a direct impact on quality-of-life of these patients ${ }^{5,9,10,11}$.
Various strategies, including antegrade and retrograde cerebral perfusion, are used for preventing neurological problems and allowing the surgeons more time for optimal repair and hemostasis has been developed 18,19,20,22. Hypothermia has been proven to decrease cellular metabolism by lowering oxygen consumption, thus reducing the adverse impact of ischemia ${ }^{10,23,24,25}$. Hypothermia, usually by way of deep hypothermic circulatory arrest (DHCA), has been used to minimize cerebral metabolic demand and protect cerebral tissue from ischemia and provide adequate neurologic protection during arch surgery ${ }^{2326,27}$.

Since the introduction of DHCA in the early 1960s; it has been increasingly used in centers 
with expertise in open heart surgery for infants, children, and adults ${ }^{14}$. The use of this technique is based on the premise that there is a safe duration of total circulatory arrest that is inversely related to the body temperature ${ }^{27,28,29}$.

Aortic arch repair in pediatric patients has traditionally been performed during a period of deep hypothermic circulatory arrest (DHCA) because it was thought to be the safest approach for cerebral protection and at the same time allowing an obstacle-free, bloodless surgical field, uncluttered field and presumed adequate neurologic protection ${ }^{4,16,30}$. Through increased survival rates after these complex operations, the significant neurodevelopmental sequel is now observed in long-term follow-up ${ }^{8,11,31}$.

Although hypothermia has proven to be a feasible means of protection of any organ, a time-dependent cascade of events resulting in brain cell injury is initiated ${ }^{23,33}$. Despite its effectiveness in reducing mortality, DHCA inevitably leads to neuropsychiatric complications, e.g. neurological dysfunction, either temporary or permanent, which can be one of the most significant risk factors influencing prognosis ${ }^{6,15}$. Long-term neurological complications may manifest as impaired neurodevelopment, with the worst outcomes being observed in newborns with complex congenital heart lesions in need for aortic arch reconstruction under prolonged periods of $\mathrm{DHCA}^{25,27}$ and 34 . Meanwhile, the risk of injury associated with DHCA is not clear, although long periods have been associated with seizures and choreoathetosis ${ }^{35}$.

The aim of the Research: The present research was conducted to examine the effect of clinical impact, particularly neurologic complications, of deep hypothermic circulatory arrest on pediatric arch surgery and to summarize the early outcomes.

\section{Patients and Methods}

One-handed and fourteen underwent full-term babies, the maximum age was 20 weeks, arch surgery includes Norwood, arch reconstruction for hypoplastic arch and interrupted aortic arch, healthy neurological status preoperative were included between January 1, 2011, and October 31,2015 . Preterm babies, age was more than 20 weeks, any procedures required deep hypothermic circulatory arrest else than the procedures described above and any preoperative neurological disabilities were excluded from the study. The medical records were reviewed for preoperative diagnosis of patients which included age at the time of operation, sex and diagnosis of the patients. Operative details including type of the operation, duration of cross-clamp and deep hypothermic circulatory arrest timing were documented. DHCA was conducted at $20{ }^{\circ} \mathrm{C}$. Postoperative outcomes, neurological complications including seizers, cerebral infarct, and duration of hospital stay were recorded.

\section{Statistical Methods}

Data were presented using descriptive statistics in the form of frequencies, percentages. In the statistical analysis, for the descriptive analysis, the categorical data were arranged in tables of absolute and relative frequencies. Data with normal distributions were presented as the mean and standard deviation, median and range (minimum, maximum), or $\mathrm{N}(\%)$.

\section{Results}

\section{Characteristics of Pediatric Patients}

The characteristics for all 114 pediatric patients are outlined in Table 1 . The median age at surgery was eight weeks (range: 1 day -20 weeks). Fifty-six pediatric patients (56.1\%) were male. Most of the pediatric patients underwent $(51.8 \%)$ pediatric patients underwent aortic arch reconstruction. Mean of circulatory arrest time was $42.58 \pm 16.71$ minutes, range from 9 to $123 \mathrm{~min}$, ischemic time was $120.23 \pm 32.13$ (60 to 190) minutes, and antegrade cerebral perfusion was performed at a mean flow rate for $17.52 \pm 2.72$ $\mathrm{mL} / \mathrm{kg} / \mathrm{min}$.

Table 1. Characteristics of Pediatric Patients 
The outcome of Antegrade Cerebral Perfusion during Deep...

\begin{tabular}{|c|c|}
\hline \multicolumn{2}{|l|}{ Demographic data } \\
\hline Age at surgery & \\
\hline Median & 8 weeks \\
\hline Range & (1 day -20 weeks) \\
\hline Female, N (\%) & $50(43.9)$ \\
\hline Male, N (\%) & $64(56.1)$ \\
\hline \multicolumn{2}{|l|}{ Diagnosis } \\
\hline Arch, N (\%) & $59(51.8)$ \\
\hline Interrupted Aortic Arch, N (\%) & $15(13.2)$ \\
\hline Norwood, N (\%) & $40(35.1)$ \\
\hline \multicolumn{2}{|l|}{ Intraoperative data } \\
\hline Circulatory arrest time (min) & $42.58 \pm 16.71$ \\
\hline Ischemic time(min) & $120.23 \pm 32.13$ \\
\hline $\begin{array}{l}\text { The flow of antegrade cerebral perfusion } \\
\mathrm{mL} / \mathrm{kg} / \mathrm{min})\end{array}$ & $17.52 \pm 2.72$ \\
\hline
\end{tabular}

Figure 1. Number of Cases per Year

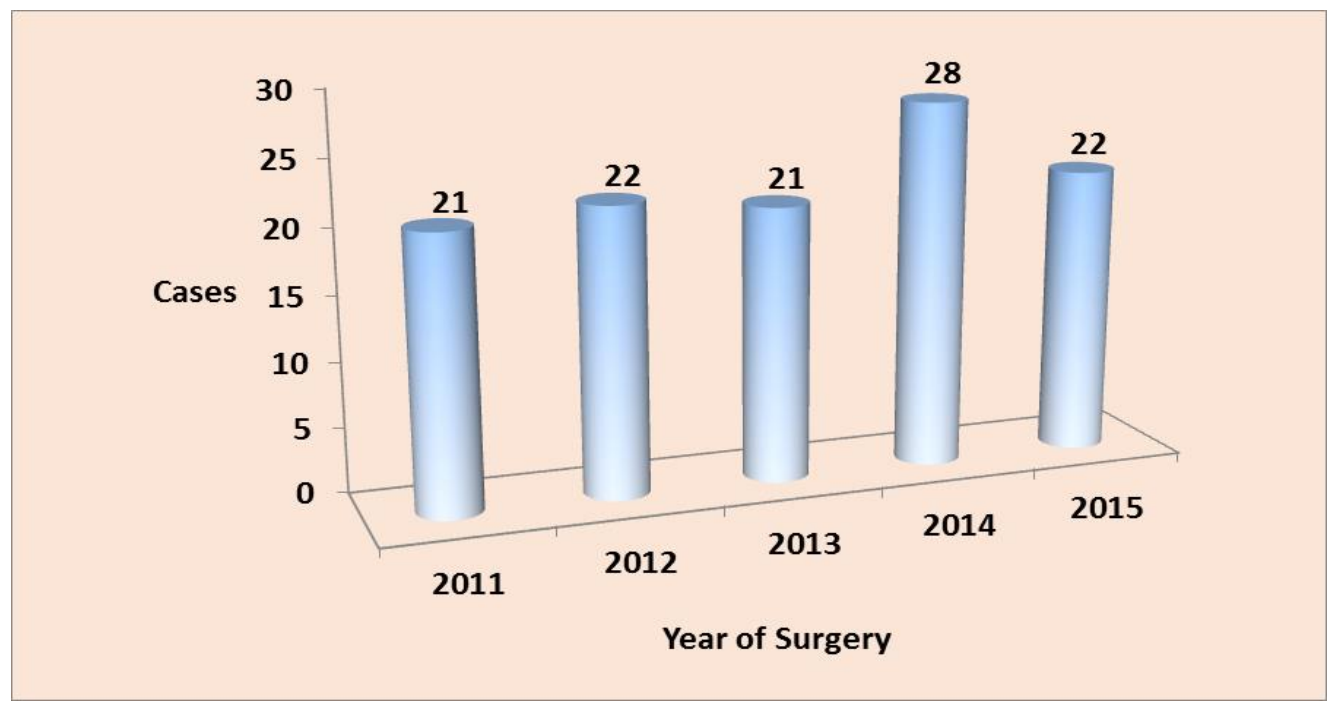

The above Histogram demonstrating a number of antegrade cerebral perfusion (from January 2011 to October 2015)

\section{Postoperative Outcomes}

The postoperative outcomes for all 114 pediatric patients were described in Table 2. There were eleven $(9.6 \%)$ deaths. Six pediatric patients $(5.3 \%)$ had a seizure after surgery. Two pediatric patients had to bleed (1.8\%). Although twenty-four pediatric patients (21.1\%) had cerebral infarct and their CT scan finding showed infarction respectively. Median postoperative lengths of hospital and ICU stay for all 114 pediatric patients were 23 days (range, 5-370 days).

Table 2. Postoperative Outcomes 


\begin{tabular}{|l|c|}
\hline \multicolumn{1}{|c|}{ Variable } & All patients (N=114) \\
\hline Outcome & $11(9.6)$ \\
\hline Death, N (\%) & $16(14.0)$ \\
\hline ICE, N (\%) & $87(76.3)$ \\
\hline Normal, N (\%) \\
\hline Seizure \\
\hline No, N (\%) & $108(94.7)$ \\
\hline Yes, N (\%) & $6(5.3)$ \\
\hline Bleeding & $112(98.2)$ \\
\hline No, N (\%) & $2(1.8)$ \\
\hline Yes, N (\%) & $90(78.9)$ \\
\hline Cerebral Infarct & $24(21.1)$ \\
\hline No, N (\%) & \\
\hline Yes, N (\%) & $24(21.1)$ \\
\hline CT Scan Finding & $90(78.9)$ \\
\hline Infarction, N (\%) & 23 days \\
\hline No, N (\%) & $(5$ day -370 days) \\
\hline $\begin{array}{l}\text { Hospital Stay } \\
\text { Median } \\
\text { Range }\end{array}$ &
\end{tabular}

\section{Discussion:}

Circulatory arrest during cardiac surgery is associated with a greater risk of postoperative neurologic abnormalities. The cerebral protection methods currently used for aortic surgery and complex open heart surgery are profound hypothermic circulatory arrest with or without retrograde cerebral perfusion, and antegrade $\operatorname{RCP}^{(3,21,22,26,29)}$.

In the present study, it was observed that, most of the pediatric patients underwent children underwent aortic arch reconstruction. The mean duration of circulatory arrest in our pediatric patients was $42.58 \pm 16.71$ minutes, ischemic time was $120.23 \pm 32.13$, and antegrade cerebral perfusion was performed at a mean flow rate for $17.52 \pm 2.72 \mathrm{~mL} / \mathrm{kg} / \mathrm{min}$. A similar study conducted by ${ }^{(1,2)}$ who supported our study represents the outcomes of deep hypothermic circulatory arrest in pediatric cardiac surgery measurement observed a target esophageal temperature of 18 and placement of an ice pack on the head. The mean duration of DHCA in patients was in Ahmed et al., study it was 20.03 \pm 10.7 minutes ${ }^{(2)}$ in Zheng et al. study it was $30.64 \pm 15.81$ minutes ${ }^{(36)}$ and in Tassani et al.it was $40 \pm 4$ min in the study of ${ }^{(3)}$
In the present study, it was observed that the incidence of postoperative complications such as seizure \& bleeding was markedly $5.3 \% \&$ $1.8 \%$ of the studied patients respectively and less than quarter of the studied patients of the patients developed cerebral infarct and their CT scan finding showed infarction respectively during deep hypothermia arrest with pediatric arch surgery. And finally, 9.6\% of the patients died in hospital. The neurological complications remain a problem in aortic arch reconstruction in neonates and infants using DHCA ${ }^{(23)}$. The findings of the current study were in agreement with those of Ahmed et al., who demonstrated that there is no difference in neurological outcome between DHCA alone and with retrograde cerebral perfusion (RCP) (2). A similar study conducted by Sarah et al., to assess the effect of deep hypothermic circulatory arrest continuing education in anesthesia reported that the circulatory arrest is typically undertaken at 18-20 $\mathrm{C}$ and a range of safe periods for DHCA have been reported at this temperature ${ }^{(28)}$.

The study of Abdelkhalik concluded that neurological complications which frightened many surgeons to adopt this DHCA technique is not very common \& it seemed that arresting 
the circulation up to $60 \mathrm{~min}$ is safe $\&$ does not affect the recovery of babies provided ${ }^{(1)}$. The results of the current study incongruity with a study conducted by Dominguez et al. who reported that neurological disorders are common after surgery of complex congenital defects, especially in cases of prolonged $\mathrm{DHCA}^{(12)}$. On the contrary of our findings, Cook et al., stated that systemic temperatures below $22^{\circ} \mathrm{C}$ might not be necessary and might be associated with a higher incidence of neurologic injury when using ACP during $\mathrm{DHA}^{(9)}$.

\section{Recommendations}

The study recommended that special facilities and specific research studies are required:

1. Use the Antegrade cerebral perfusion during deep hypothermic circulatory arrest with cerebral oximetry monitoring and cell saver.

2. Long-term neurodevelopmental follow-up of these children is required to evaluate the late outcomes of ACP.

3. The study has to be conducted with a larger group in a different setting for better generalization of the results.

\section{Conclusion}

Based on the study findings, it could be concluded that the aortic arch reconstruction with Antegrade cerebral perfusion during the deep hypothermic circulatory arrest is accompanied by a lower risk of neurological complications. Thus, the use of Antegrade cerebral perfusion during deep hypothermic circulatory arrest helps in increase timing safely.

\section{References}

1. Abdelkhalik $M$ and El-Sawy $H$ (2002): The use of deep hypothermia \& total circulatory arrest in pediatric cardiac surgery (Egyptian experience). J Egypt Soc Cardiothorac Surg., 10(3):415e21.

2. Ahmed A. Elassal, Ragab S. Debis, Mazen S. Faden, Ahmed H. Alqari, Mahmoud A. Abdulaziz, Osman O and Al Radi (2016): Outcomes of deep hypothermic circulatory arrest in pediatric cardiac surgery: A single center experience, Journal of the Egyptian Society of Cardio-Thoracic Surgery, 24:228e231.

3. Algra SO, Schouten AN, van Oeveren W, van der Tweel I, Schoof PH, Jansen NJ and Haas F (2012): Low-flow antegrade cerebral perfusion attenuates early renal and intestinal injury during neonatal aortic arch reconstruction. J Thorac Cardiovasc Surg., 144:1323-1328.

4. Asou T, Kado H, Imoto Y, Shiokawa Y, Tominaga $R$ and Kawachi $Y$ (1996): Selective cerebral perfusion technique during aortic arch repair in neonates. Ann Thorac Surg., 61:1546-8.

5. Bashir M, Shaw M, Desmond M, Kuduvalli M, Field M (2013): Cerebral protection in hemi-aortic arch surgery. Ann Cardiothorac Surg., 2:239-44.

6. Bonser RS, Ranasinghe AM, and Loubani M (2011): Evidence, lack of evidence, controversy, and debate in the provision and performance of the surgery of acute type A aortic dissection. J Am Coll Cardiol., 58:245574.

7. Chock VY, Amir G, Davis CR, Ramamoorthy C, Riemer RK, Ray D, Giffard RG and Reddy VM (2006): Antegrade cerebral perfusion reduces apoptotic neuronal injury in a neonatal piglet model of cardiopulmonary bypass. J Thorac Cardiovasc Surg., 131:659-665.

8. Clancy RR, McGaurn SA, and Wernovsky G (2000): Preoperative risk-ofdeath prediction model in heart surgery with deep hypothermic circulatory arrest in the neonate. J Thorac Cardiovasc Surg., 119:34757.

9. Cook RC, Gao M, Macnab AJ, Fedoruk LM, Day N and Janusz MT(2006): Aortic arch reconstruction: Safety of moderate hypothermia and antegrade cerebral perfusion during the systemic circulatory arrest. J Cardiovasc Surg., 21: 158 - 164.

10. Cooper WA, Duarte IG, Thourani VH, Nakamura M, and Wang NP and Brown 
WM (2000): Hypothermic circulatory arrest causes multisystem vascular endothelial dysfunction and apoptosis. Ann Thorac Surg., 69:696-702.

11. Dillard DH, Mori H, and Merendino KA (1971): Correction of heart disease in infancy utilizing deep hypothermia and total circulatory arrest. J Thorac Cardiovasc Surg., 61:64-9.

12. Dominguez TE, Wernovsky G, and Gaynor JW (2007): Cause and prevention of central nervous system injury in neonates undergoing cardiac surgery. Semin Thorac Cardiovasc Surg., 19:269-77.

13. Elefteriades JA, (2010): What is the best method for brain protection in surgery of the aortic arch? Straight DHCA. Cardiol Clin, 28:381-7.

14. Gaynor JW, Nicolson SC, Jarvik GP, Wernovsky G, Montenegro LM and Burnham NB (2005): Increasing duration of deep hypothermic circulatory arrest is associated with an increased incidence of postoperative electroencephalographic seizures. J Thorac Cardiovasc Surg., 130: $1278-86$.

15. Givehchian $M$, Beschorner R, Ehmann C, Frauenlob L, Morgalla M, Hashemi B, Ziemer $G$ and Scheule AM (2010): Neuroprotective effects of erythropoietin during the deep hypothermic circulatory arrest. Eur J Cardiothorac Surg., 37: 662-668.

16. Greeley WJ, Kern FH, Ungerleider RM, Boyd III JL, Quill T and Smith LR (1991): The effect of the hypothermic cardiopulmonary bypass and total circulatory arrest on cerebral metabolism in neonates, infants, and children. J Thorac Cardiovasc Surg., 101: 783-794.

17. Griepp R (2007): Panel Discussion: Session II-Aortic Arch. Ann Thorac Surg., 83: S824-31.

18. Griepp $\mathbf{R B}(2001)$ : Cerebral protection during aortic surgery. J Thorac Cardiovasc Surg., 121:425-427.
19. Halushka M (2012): Pathology of the aorta. Surg Pathol Clin., 5:417-33.

20. Hammel JM, Deptula JJ, Karamlou T, Wedemeyer E, Abdullah I, and Duncan KF (2013): Newborn aortic arch reconstruction with descending aortic cannulation improves postoperative renal function. Ann Thorac Surg., 96:1721-6.

21. Hofer A, Haizinger B, Geiselseder G, Mair R, Rehak $P$ and Gombotz $H$ (2005): Monitoring of selective antegrade cerebral perfusion using near infrared spectroscopy in neonatal aortic arch surgery. Eur J Anaesthesiol., 22:293-298.

22. Lee TY, Safi HJ, and Estrera AL (2011): Cerebral perfusion in aortic arch surgery: antegrade, retrograde, or both? Tex Heart Inst J., 38:674-677.

23. McCullough JN, Zhang N, Reich DL, Juvonen TS, Klein JJ and Spielvogel D (1999): Cerebral metabolic suppression during a hypothermic circulatory arrest in humans. Ann Thorac Sur., 67:1895-9.

24. Milewski RK, Pacini D, Moser GW, Moeller P, Cowie D and Szeto WY (2010): Retrograde and antegrade cerebral perfusion: results in short elective arch reconstructive times. Ann Thorac Surg., 89:1448-57.

25. Newburger JW, Jonas RA, and Wernovsky G (1993): A comparison of the perioperative neurologic effects of hypothermic circulatory arrest versus low-flow cardiopulmonary bypass in infant heart surgery. N Engl J Med., 329:1057-64.

26. Pacini D, Di Marco L, and Leone A, Di Bartolomeo R, Sodeck G, Englberger L, Carrel T, Czerny M(2012): Antegrade selective cerebral perfusion and moderate hypothermia in aortic arch surgery: clinical outcomes in elderly patients. Eur J Cardiothorac Surg., 42:249-253.

27. Rappaport LA, Wypij D, and Bellinger DC (1998): Relation of seizures after cardiac surgery in early infancy to neurodevelopmental outcome. Boston Circulatory Arrest Study Group. Circulation, 97:773-9. 
28. Sarah C, Joseph EA, and Andrew AK (2010): Deep hypothermic circulatory arrest continuing education in anesthesia. Crit Care Pain, 10:138e42.

29. Senanayake E, Komber M, Nassef A, Massey N and Cooper G (2012): Effective cerebral protection using near-infrared spectroscopy monitoring with antegrade cerebral perfusion during aortic surgery. J Card Surg., 27:211-216.

30. Stecker MM, Cheung AT, Pochettino A, Kent GP, Patterson $T$ and Weiss SJ (2001): Deep hypothermic circulatory arrest: I. Effects of cooling on electroencephalogram and evoked potentials. Ann Thorac Surg., 71:14-21.

31. Tabbutt S, Nord AS, and Jarvik GP (2008): Neurodevelopmental outcomes after staged palliation for hypoplastic left heart syndrome. Pediatrics, 121:476-83.

32. Tassani P, Barankay A, Haas F, Paek SU, Heilmaier M and Hess J (2002): Cardiac surgery with deep hypothermic circulatory arrest produces less systemic inflammatory response than low-flow cardiopulmonary bypass in newborns. J Thorac Cardiovasc Surg., 123(4):648e54.

33. Urbanski PP, Lenos A, Bougioukakis P, Neophytou I, Zacher $M$ and Diegeler $A($ 2012): Mild-to-moderate hypothermia in aortic arch surgery using circulatory arrest: a change of paradigm? Eur J Cardiothorac Surg., 41:18591.

34. Williams JB, Peterson ED, Zhao Y, O'Brien SM, Andersen ND and Miller DC (2012): Contemporary results for proximal aortic replacement in North America. J Am Coll Cardiol., 60:1156-62.

35. Wypij D, Newburger JW, and Rappaport LA (2003): The effect of duration of deep hypothermic circulatory arrest in infant heart surgery on late neurodevelopment: the Boston Circulatory Arrest Trial. J Thorac Cardiovasc Surg., 126:1397-403. 